\title{
Proactive Use of High-Flow Nasal Cannula With Critically Ill Subjects
}

\author{
Keith D Lamb RRT RRT-ACCS, Sarah K Spilman MA, Trevor W Oetting RRT, \\ Julie A Jackson RRT RRT-ACCS, Matthew W Trump DO, and Sheryl M Sahr MD MSc
}

\begin{abstract}
INTRODUCTION: It has been suggested that use of a high-flow nasal cannula (HFNC) could be a first-line therapy for patients with acute hypoxic respiratory failure. The purpose of this study was to determine if protocolized use of HFNC decreases unplanned intubation and adverse outcomes in an ICU population. METHODS: The study was a prospective evaluation of 2 cohorts who received HFNC per protocol. Control groups were retrospective selections of subjects who received HFNC in the pre-protocol period. Cohort $1(n=88)$ received mechanical ventilation for $\geq 24 \mathrm{~h}$ and was extubated directly to HFNC following strict protocol criteria. Cohort $2(n=83)$ were placed on HFNC when oxygen requirements escalated ( $>4$ L/min). RESULTS: Cohort 1 did not differ from its control group in mortality, hospital stay, or ICU days, but there were significant decreases in incidence of Gram-negative pulmonary infection $(30 \% \mathrm{vs} 9 \%, P=.001)$ and use of bronchodilator therapy $(81 \%$ vs $61 \%, P=.008)$. Failed extubation rates were nearly identical across groups, but time to re-intubation was shorter in the protocol group ( $24 \mathrm{vs} 13 \mathrm{~h}, P=.19)$. Cohort 2 did not differ significantly from its control group in intubation rates or mortality, but subjects managed by protocol experienced significant decreases in ICU days (4 vs $3 \mathrm{~d}, P=.03$ ) and hospital days (12 vs $8 \mathrm{~d}, P=.007)$. There was a trend toward fewer hours on HFNC (33 vs $24 \mathrm{~h}, P=.10$ ) and faster time to intubation when HFNC failed (19 vs $9 \mathrm{~h}, P=.08$ ). CONCLUSIONS: Extubation to HFNC led to a significant decrease in pulmonary infections and bronchodilator therapy in Cohort 1 but did not reduce length of stay or rates of failed extubation. When HFNC was used early and per protocol (Cohort 2), ICU and hospital lengths of stay were reduced and HFNC was initiated more quickly when the need for respiratory support escalated. Key words: highflow nasal cannula; respiratory failure; mechanical ventilation; postextubation management; reintubation; pulmonary infection. [Respir Care 2018;63(3):259-266. (C) 2018 Daedalus Enterprises]
\end{abstract}

\section{Introduction}

High-flow nasal cannula (HFNC) has gained popularity due to its ease of use, comfort, and efficient delivery of humidified high-flow oxygen. ${ }^{1-4}$ It has been used success-

\footnotetext{
Mr Lamb, Mr Oetting, and Ms Jackson are affiliated with the Department of Respiratory Therapy, UnityPoint Health, Des Moines, Iowa. Ms Spilman is affiliated with the Department of Trauma Services, UnityPoint Health, Des Moines, Iowa; Dr Trump is affiliated with the Department of Pulmonology and Critical Care, The Iowa Clinic, and with the Department of Pulmonology and Critical Care, UnityPoint Health, Des Moines, Iowa. Dr Sahr is affiliated with the Department of Trauma Surgery, The Iowa Clinic, and with the Department of Trauma Services, UnityPoint Health, Des Moines, Iowa.

Supplementary material related to this paper is available at http:// www.rcjournal.com.
}

fully with medical ICU patients, as well as in postoperative cardiac, vascular, and trauma populations, to reduce work of breathing, improve accuracy of delivered $\mathrm{F}_{\mathrm{IO}_{2}}$, provide minor positive pressure delivery to airways, and wash out $\mathrm{CO}_{2} \cdot{ }^{1,2,5}$ The literature suggests that early HFNC use may result in improved outcomes, but optimal patient characteristics, flows, $\mathrm{F}_{\mathrm{IO}_{2}}$ range, and timing are unclear. ${ }^{3}$ Gaunt et $\mathrm{al}^{6}$ found that subjects who received HFNC earlier rather than later in the hospital stay had reduced ICU

\footnotetext{
Mr Lamb presented an earlier version of this work at the annual conference of the Society of Critical Care Medicine, held January 21-25, 2017, in Honolulu, HI, and Dr Trump presented at the American Thoracic Society International Conference, held May 19-24, 2017, in Washington, DC.
} 
and post-ICU lengths of stay, even after controlling for mechanical ventilation. It has been suggested that HFNC could be a first-line therapy for patients with acute hypoxic respiratory failure. ${ }^{6,7}$

See the Related Editorial on Page 367

HFNC has been used to resolve postextubation hypoxemia and to prevent re-intubation in certain patient populations because of its ability to reduce upper airway dryness after extubation, improve management of respiratory secretions, and potentially have a protective effect on mucociliary function. ${ }^{1,7-10}$ In addition, HFNC conditions the inspired gas, allowing for improved oxygenation, and alleviates tracheal mucosa inflammation after intubation. ${ }^{8,9}$ In subjects at low risk for re-intubation, Hernández et $\mathrm{al}^{11}$ demonstrated that, compared to conventional $\mathrm{O}_{2}$ therapy, only $1.5 \%$ of subjects extubated to HFNC required re-intubation for respiratory failure, compared to $9 \%$ in the control group.

There are, however, conflicting data regarding the benefits of HFNC postextubation. ${ }^{12,13}$ In a study of surgical subjects who received $\mathrm{HFNC}$ versus standard $\mathrm{O}_{2}$ therapy after postoperative extubation, there were no significant differences in rates of hypoxemia, need for $\mathrm{O}_{2}$ therapy after HFNC, pulmonary complications, or length of stay. ${ }^{13}$ Hernández et al ${ }^{14}$ investigated HFNC use in high-risk subjects, and re-intubation rates for respiratory failure were nearly identical (5\%) for subjects receiving HFNC and noninvasive ventilation (NIV). Finally, a recent meta-analysis found no difference in rates of re-intubation for subjects extubated to HFNC compared to usual care. ${ }^{15}$

Some evidence supports the use of HFNC to prevent intubation in patients with an escalating need for respiratory support, but studies are limited by small sample sizes, retrospective design, and varying severity of respiratory distress. In a small prospective study of subjects requiring

\footnotetext{
Mr Lamb discloses relationships with Medtronic, and Fisher \& Paykel. Dr Trump discloses a relationship with Fisher \& Paykel. The other authors have disclosed no conflicts of interest.
}

At the time of this study, Mr Lamb was affiliated with the Department of Respiratory Therapy, UnityPoint Health, Des Moines, Iowa. He is now affiliated with Inova Fairfax, Falls Church, VA.

At the time of this study, Dr Sahr was affiliated with the Department of Trauma Surgery, The Iowa Clinic. She is now affiliated with Sanford Medical Center, Fargo, ND.

Correspondence: Sarah K Spilman MA, Trauma Services, UnityPoint Health, 1200 Pleasant Street, Des Moines, IA 50309. E-mail: sarah.spilman@unitypoint.org.

DOI: $10.4187 /$ respcare.05793

\section{QUICK LOOK}

\section{Current knowledge}

High-flow nasal cannula (HFNC) has promise as a firstline therapy for critically ill patients with acute hypoxic respiratory failure. It has been shown to resolve postextubation hypoxemia and to prevent re-intubation in certain patient populations. In addition, there is evidence that HFNC reduces intubation rates if used prophylactically as the need for respiratory support escalates.

\section{What this paper contributes to our knowledge}

When HFNC was protocolized and used immediately after extubation, there was a significant decrease in pulmonary infection rates and bronchodilator therapy use, but the protocol did not reduce length of stay or prevent re-intubation. When the HFNC protocol was initiated proactively as the need for respiratory support escalated, ICU and hospital lengths of stay were reduced and respiratory distress was recognized more quickly.

$>9 \mathrm{~L} / \mathrm{min}$ of $\mathrm{O}_{2}$ to achieve $\mathrm{S}_{\mathrm{pO}_{2}} \geq 92 \%$, HFNC was associated with reduced breathing frequency, dyspnea, and pulse oximetry, but one quarter of subjects required invasive mechanical ventilation. ${ }^{16}$ In contrast, in subgroup analyses of a large multi-center trial, subjects with moderate to severe ARDS who were placed on HFNC had significantly lower intubation rates when compared with subjects who received standard $\mathrm{O}_{2}$ or NIV..${ }^{17}$ It is unknown, however, what role HFNC should play when respiratory support requirements escalate. We found only one study that examined subjects as the need for respiratory support began to escalate. Parke et al ${ }^{18}$ found that only $10 \%$ of subjects who received HFNC for mild to moderate hypoxemic respiratory failure required intubation, compared to $30 \%$ in the control group (standard face mask).

Our study evaluated the prophylactic use of HFNC in 2 critically ill populations: newly extubated subjects and subjects with an escalating need for respiratory support. We evaluated whether protocols that standardize HFNC use in these populations prevented unanticipated respiratory compromise and adverse outcomes. Specifically, we hypothesized that receiving HFNC per protocol would reduce the rate of unplanned intubation or re-intubation in a heterogeneous ICU population.

\section{Methods}

Our study was a prospective evaluation of adults at Iowa Methodist Medical Center, UnityPoint Health, Des Moines, Iowa, which is a tertiary hospital with a mixed 


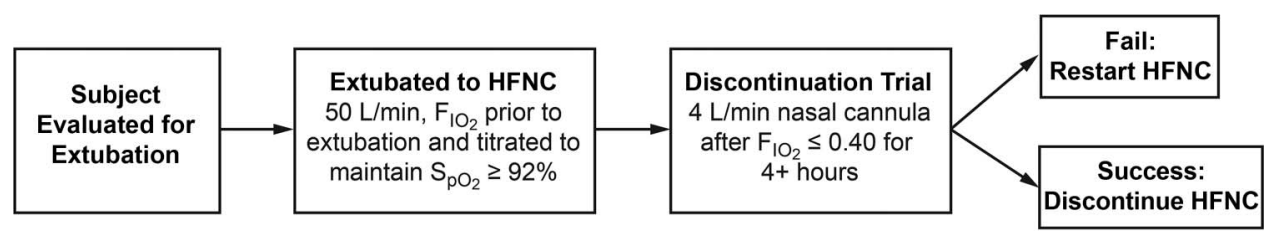

Fig. 1. Study protocol for cohort 1.

medical, surgical, and trauma ICU. HFNC was delivered via AIRVO (Fisher \& Paykel, Auckland, New Zealand); at the time of the study, the modality was available only in the ICU. The devices were loaned to the study hospital by Fisher \& Paykel; no funding was received from the manufacturer to conduct this study.

There were 2 populations in this study: Cohort 1 and Cohort 2 . The investigation was a parallel, 2-group design. To determine sample sizes in both cohorts, power analyses were tested for the intervention to reduce intubation and re-intubation using the Gaunt et $\mathrm{al}^{6}$ study for comparison. To detect a moderate effect size with a power of $0.80,{ }^{19}$ each cohort required a sample size of between 64 and 99 subjects. A subject could be in both cohorts only if HFNC was received as part of escalation of care (Cohort 2) and HFNC was administered after extubation (Cohort 1). The study was approved by the Institutional Review Board at the study hospital.

\section{Procedures}

Cohort 1: Extubation to HFNC. All subjects in Cohort 1 were admitted to the hospital during a 5-month study period (July-November 2015) and received mechanical ventilation in the ICU for $24 \mathrm{~h}$ or more. The study protocol is illustrated in Figure 1. Subjects were assessed for extubation readiness on a daily basis per hospital protocol (see the supplementary materials at http://www.rcjournal. com). ${ }^{20}$ After extubation, they were placed immediately on HFNC with initial flow at $50 \mathrm{~L} / \mathrm{min}$ and $\mathrm{F}_{\mathrm{IO}_{2}}$ set to the last documented level and titrated to maintain $\mathrm{S}_{\mathrm{pO}_{2}} \geq 92 \%$. This $92 \%$ saturation threshold was chosen due to wellknown physiologic behavior, which is outlined within the description of the oxyhemoglobin dissociation curve. ${ }^{21-23}$ According to this principle, as the curve becomes flattened at about $90 \%$ saturation, there is no relative value in the $\mathrm{P}_{\mathrm{aO}_{2}}$ increasing above $60 \mathrm{~mm} \mathrm{Hg}$. Conversely, as the hemoglobin becomes desaturated, the opposite is true. Creating a threshold of $92 \%$ gives the clinician some cushion should the patient deteriorate.

When the $\mathrm{F}_{\mathrm{IO}_{2}}$ requirement was $\leq 40$ for 4 consecutive hours, a discontinuation trial off HFNC was attempted using low-flow nasal cannula $(4 \mathrm{~L} / \mathrm{min})$. If subjects were unable to maintain target saturations, they were restarted on HFNC at the last documented setting. If subjects maintained their saturations, HFNC was discontin- ued. During the study period, the protocol was used 104 times; however, 6 encounters were excluded because the subjects did not receive mechanical ventilation for $>24 \mathrm{~h}$ and 10 subjects received the protocol more than once. This resulted in 88 unique subjects in the study group for Cohort 1.

After the study period concluded, an equal number of subjects were identified retrospectively as a pre-protocol control group. Subjects in the control group were admitted prior to the study period (January-June 2015) and received mechanical ventilation for $\geq 24 \mathrm{~h}$. Postextubation oxygenation modality was not guided by protocol but rather was selected at the discretion of the physician and respiratory therapist at the time of extubation. In the control group, subjects were most commonly extubated to nasal cannula, HFNC (Optiflow, Fisher \& Paykel, Auckland, New Zealand), or bi-level positive airway pressure (BiPAP, Philips Respironics, Murrysville, Pennsylvania). One hundred forty-nine subject encounters were reviewed for study inclusion criteria; 61 (41\%) were excluded from the control group because of tracheostomy $(n=9)$, failure to extubate or discharged from ICU with mechanical ventilation $(n=26)$, or terminal extubation $(n=26)$.

Cohort 2: Escalation to HFNC. All Cohort 2 subjects were admitted to the hospital during a 7-month study period (July 2015 to January 2016) and demonstrated a need for increased respiratory support $(>4 \mathrm{~L}$ nasal cannula or $\geq 36 \mathrm{~F}_{\mathrm{IO}_{2}}$ to keep $\mathrm{S}_{\mathrm{pO}_{2}} \geq 92 \%$ ). The study protocol is illustrated in Figure 2. Initial HFNC settings were $50 \mathrm{~L} / \mathrm{min}$, and $\mathrm{F}_{\mathrm{IO}_{2}}$ was titrated to maintain $\mathrm{S}_{\mathrm{pO}_{2}} \geq$ $92 \%$. When the $\mathrm{F}_{\mathrm{IO}_{2}}$ requirement was $\leq 40$ for 4 consecutive hours, a trial off the HFNC was attempted using a low-flow nasal cannula $(4 \mathrm{~L} / \mathrm{min})$. The protocol was used 98 times during the study period; however, 8 encounters were excluded from analyses because the subjects received mechanical ventilation prior to HFNC, 1 subject was excluded because of death within $24 \mathrm{~h}$ of hospital admission, and 6 were excluded because of protocol violations (receiving $0-3 \mathrm{~L} / \mathrm{min}$ nasal cannula prior to HFNC). This resulted in 83 unique subjects in the study group for Cohort 2 .

After the study period concluded, an equal number of subjects were identified retrospectively as a pre-protocol control group. The control group was composed primarily 


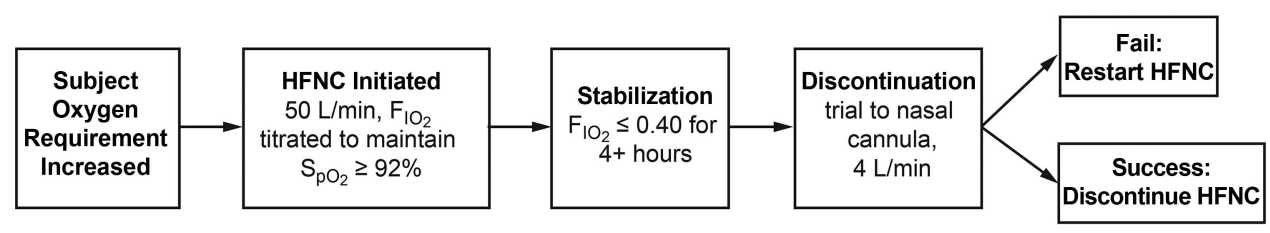

Fig. 2. Study protocol for cohort 2.

of subjects who were analyzed in a previous study. ${ }^{6}$ The data were reviewed to ensure that all subjects received HFNC as part of escalation of care in the ICU when the $\mathrm{O}_{2}$ requirement was met $(>4 \mathrm{~L} / \mathrm{min})$, and subjects were excluded if HFNC was administered after mechanical ventilation.

\section{Study Variables}

For both cohorts, demographic variables included age and sex. Subjects were considered do-not-resuscitate if they had a do-not-resuscitate order or a do-not-intubate order at any time during the hospital stay. Comorbidities were abstracted from the medical record after discharge, including history of cardiac disease, respiratory disease, and smoking (current or former). Bronchodilator therapy indicates whether the subject received ipratropium bromide and/or albuterol during the ICU stay.

The primary outcome of interest was unplanned intubation. In Cohort 1, we noted a failed extubation if a subject was reintubated for respiratory reasons within $72 \mathrm{~h}$ of extubation. For Cohort 2, we noted intubation after HFNC if a subject received mechanical ventilation within $72 \mathrm{~h}$ of HFNC initiation. Additional outcomes included mortality, lengths of stay in the hospital and in the ICU, and pulmonary infection. Pulmonary infection was obtained from culture data and indicated whether a subject had a Gram-negative pulmonary infection (eg, Acinetobacter, Klebsiella, Pseudomonas, Escherichia coli) while endotracheally intubated. At the study institution, cultures were obtained at the discretion of the attending physician when there was clinical suspicion of infection.

\section{Statistical Procedures}

All analyses were performed with IBM SPSS Basic Statistics for Windows, version 20.0 (IBM Armonk, New York). Descriptive statistics were examined and reported for continuous data as medians and interquartile ranges; categorical data were reported as counts and percentages. Statistical tests were 2-tailed and based on a 0.05 significance level. Because data were not normally distributed and sample sizes were unequal, differences between medians were assessed using the Kruskal-Wallis one-way anal- ysis of variance. Differences between nominal variables were assessed using the chi-square test.

\section{Results}

\section{Cohort 1. Extubation to HFNC}

During the study period, 88 subjects met inclusion criteria for Cohort 1 and were managed by HFNC protocol; this was compared to a pre-protocol control group of 88 subjects. As shown in Table 1, the groups were similar in age, sex, acuity, and medical comorbidities. There were no statistically significant differences in ICU days, hospital days, or mortality.

Extubation failure rates were similar across the preprotocol and protocol phases (11\% and 10\%, respectively). For subjects who required re-intubation, the protocol group averaged more days between ICU admission and first extubation, as well as more days between first extubation and ICU discharge. Median time to re-intubation was reduced by $46 \%$ in the protocol group, but the difference was not statistically significant. In the protocol phase, there were significant decreases in incidence of Gram-negative pulmonary infection and use of bronchodilator therapy.

\section{Cohort 2. Escalation to HFNC}

Eighty-three subjects met inclusion criteria for Cohort 2 ; this was compared to a pre-protocol control group of 83 subjects. The groups were similar in demographics and comorbidities (Table 2). While intubation rates were similar across phases, subjects in the protocol group were intubated approximately $10 \mathrm{~h}$ earlier than subjects in the pre-protocol group $(P=.08)$.

Subjects managed without HFNC protocol had significantly more ICU days ( 4 vs $3 \mathrm{~d}, P=.03$ ) and hospital days (12 vs $8 \mathrm{~d}, P=.007)$, and HFNC was initiated less quickly when the need for respiratory support escalated $(1.4 \mathrm{~h}$ vs $0.3 \mathrm{~h}, P<.001)$. Mortality decreased from $28 \%$ in the pre-protocol group to $21 \%$ in the protocol group, but the difference was not statistically significant. 
Table 1. Cohort 1: Extubation to HFNC

\begin{tabular}{|c|c|c|c|}
\hline Variable & Pre-Protocol $(n=88)$ & Protocol $(n=88)$ & $P$ \\
\hline Age, median (IQR) y & $68(56-76)$ & $62(51-73)$ & .062 \\
\hline Male, $n(\%)$ & $48(54 \%)$ & $51(58 \%)$ & .76 \\
\hline Do-not-resuscitate at any time, $n(\%)$ & $28(32 \%)$ & $23(26 \%)$ & .51 \\
\hline \multicolumn{4}{|l|}{ Comorbidities, $n(\%)$} \\
\hline Current or former smoker & $19(22 \%)$ & $20(23 \%)$ & .99 \\
\hline Cardiac disease & $46(52 \%)$ & $46(52 \%)$ & .99 \\
\hline Respiratory disease & $36(41 \%)$ & $31(35 \%)$ & .54 \\
\hline Mortality, $n(\%)$ & $11(13 \%)$ & $8(9 \%)$ & .63 \\
\hline Gram-negative pulmonary infection, $n(\%)$ & $26(30 \%)$ & $8(9 \%)$ & .001 \\
\hline Bronchodilator therapy, $n(\%)$ & $71(81 \%)$ & $54(61 \%)$ & .008 \\
\hline Hospital stay, median (IQR) d & $13(8-22)$ & $14(9-23)$ & .27 \\
\hline Total ICU stay, median (IQR) d & $7(4-11)$ & $7(4-11)$ & .79 \\
\hline Time between ICU admission and first extubation, median (IQR) $d$ & $4(2-7)$ & $4(2-7)$ & .82 \\
\hline HFNC duration, median (IQR) d & NA & $0.6(0.3-1.1)$ & NA \\
\hline $\mathrm{P}_{\mathrm{aO}_{2}} / \mathrm{F}_{\mathrm{IO}_{2}}$ ratio before $\mathrm{HFNC}$, median (IQR) & $280(220-361)$ & $273(217-360)$ & .95 \\
\hline Failed extubation, $n(\%)$ & $10(11 \%)$ & $9(10 \%)$ & .99 \\
\hline Time between ICU admission and first extubation, median (IQR) d & $4(2-8)$ & $6(4-11)$ & .21 \\
\hline Time between first extubation and ICU discharge, median (IQR) d & $8(6-10)$ & $15(11-16)$ & .041 \\
\hline Time to re-intubation, median (IQR) h & $24(7-57)$ & $13(5-30)$ & .19 \\
\hline \multicolumn{4}{|l|}{$\begin{array}{l}n=176 \text { subjects } \\
\text { HFNC = high-flow nasal cannula } \\
\text { IQR }=\text { interquartile range } \\
\mathrm{NA}=\text { not applicable }\end{array}$} \\
\hline
\end{tabular}

Table 2. Cohort 2: Escalation to HFNC

\begin{tabular}{|c|c|c|c|}
\hline Variable & Pre-Protocol $(n=83)$ & Protocol $(n=83)$ & $P$ \\
\hline Age, median (IQR) & $65(56,77)$ & $69(54,77)$ & .36 \\
\hline Male, $n(\%)$ & $45(54 \%)$ & $45(54 \%)$ & .99 \\
\hline Do-not-resuscitate at any time, $n(\%)$ & $38(46 \%)$ & $32(39 \%)$ & .43 \\
\hline \multicolumn{4}{|l|}{ Comorbidities, $n(\%)$} \\
\hline Current or former smoker & $56(68 \%)$ & $53(68 \%)$ & .74 \\
\hline Cardiac disease & $47(57 \%)$ & $52(63 \%)$ & .53 \\
\hline Respiratory disease & $51(61 \%)$ & $53(64 \%)$ & .87 \\
\hline Mortality, $n(\%)$ & $23(28 \%)$ & $17(21 \%)$ & .36 \\
\hline Gram-negative pulmonary infection, $n(\%)$ & $3(4 \%)$ & $1(1 \%)$ & .62 \\
\hline Bronchodilator therapy, $n(\%)$ & $58(70 \%)$ & $49(59 \%)$ & .19 \\
\hline Hospital stay, median (IQR) d & $12(7-20)$ & $8(5-14)$ & .007 \\
\hline Total ICU stay, median (IQR) d & $4(3-7)$ & $3(2-5)$ & .03 \\
\hline Time between $4 \mathrm{~L} / \mathrm{min}$ need and HFNC initiation, median (IQR) $\mathrm{h}$ & $1.4(0.3-3.3)$ & $0.3(0.1-0.8)$ & $<.001$ \\
\hline Intubated within $72 \mathrm{~h}$ of HFNC initiation & $12(15 \%)$ & $11(13 \%)$ & .99 \\
\hline Time between HFNC initiation and intubation $\mathrm{h}$ & $19(12-42)$ & $9(2-24)$ & .08 \\
\hline Mechanical ventilator duration, median (IQR) d & $5.2(2.1-12.9)$ & $5.0(2.0-8.5)$ & .62 \\
\hline HFNC duration, median (IQR) h & $33(15-60)$ & $24(10-52)$ & .10 \\
\hline Post-HFNC duration, median (IQR) d & $5(2-13)$ & $6(3-9)$ & .75 \\
\hline \multicolumn{4}{|l|}{$\begin{array}{l}n=168 \text { subjects } \\
\text { HFNC = high-flow nasal cannula } \\
\text { IQR = interquartile range }\end{array}$} \\
\hline
\end{tabular}




\section{HFNC Use in CRitically Ill SubJects}

\section{Discussion}

HFNC has become a popular modality of respiratory support for critically ill patients, both as a postextubation therapy modality and as a preventive modality when patient respiratory status begins to deteriorate. Our study examined the utilization of HFNC for newly extubated subjects and those with escalating respiratory support requirements. Rates of unplanned intubation did not differ between the pre-protocol and protocol groups for either cohort. When subjects failed HFNC, however, time to intubation or re-intubation was approximately $10 \mathrm{~h}$ faster in the protocol groups, suggesting that HFNC protocols led to earlier recognition of respiratory failure and faster escalation of therapy. The protocol was efficacious in this mixed patient population, and results may be generalizable to broad, critically ill populations.

The effect of HFNC on length of stay was negligible in the postextubation cohort (Cohort 1), which is consistent with the literature, ${ }^{3,15}$ but hospital and ICU lengths of stay were shorter in the protocol phase for subjects with an increasing need for respiratory support (Cohort 2). This was an unexpected finding, as the introduction of a new protocol had the potential to lengthen the hospital stay by delaying discharge from ICU because HFNC is not available on the general in-patient floor at the study hospital. It is possible that HFNC may ultimately be useful for treating floor patients with mild to moderate hypoxemia, reducing unnecessary increases in level of care, but this hypothesis cannot be tested until HFNC therapy is available outside the ICU.

The pre-protocol and protocol groups in Cohort 1 averaged $4 \mathrm{~d}$ of mechanical ventilation prior to extubation. This is much longer than the average duration of mechanical ventilation in the Hernandez et $\mathrm{al}^{11}$ population (1-2 d) that was preselected to be at low-risk for extubation failure, as well as in other studies with populations that were extubated within $24 \mathrm{~h}$ of major surgery. ${ }^{12,13}$ The longer the duration of mechanical ventilation, the greater the risk of extubation failure. Our results might help shed new light on patients with moderate to severe disease who were excluded from earlier investigations.

The protocol group in Cohort 1 experienced a dramatic reduction in Gram-negative pulmonary infection. Other studies on postextubation pulmonary infection have focused on pneumonia ${ }^{13}$ or ventilator-associated pneumonia, ${ }^{7,11}$ but we selected Gram-negative infections as an outcome because they are associated with healthcare-acquired conditions that coexist with mechanical ventilation. During intubation, the artificial airway can provide a direct pathway for bacteria to colonize the lower airways and lead to lung infection. When compared to other $\mathrm{O}_{2}$ delivery devices, HFNC may be a superior modality because there is less mucociliary de- struction and increased secretion clearance. ${ }^{1,15}$ Furthermore, intermediary devices, such as those that provide 6-15 L/min of supplemental $\mathrm{O}_{2}$, are unable to provide appropriate humidification. Normal respiratory physiology provides approximately $36-40 \mathrm{mg} / \mathrm{L}$ with an optimal required moisture of $44 \mathrm{mg} / \mathrm{L}(100 \%$ relative humidity at $37^{\circ} \mathrm{C}$ ). ${ }^{24}$ Humidity levels below $25 \mathrm{mg} / \mathrm{L}$ for $1 \mathrm{~h}$ or $30 \mathrm{mg} / \mathrm{L}$ for $24 \mathrm{~h}$ or more are associated with airway mucosal dysfunction. ${ }^{25}$ In addition, previous evaluations have demonstrated that the unheated bubble humidifiers typically used in these intermediary devices perform no better than devices without humidification. ${ }^{26}$ This may explain in part why respiratory infection rates are lower when intermediary devices are bypassed and HFNC is used instead.

Bronchodilator use decreased dramatically in both cohorts, but the decrease was statistically significant in Cohort 1. This finding is consistent with our earlier work ${ }^{6,27}$ and with other literature. ${ }^{28}$ Prior to initiation of respiratory protocols at our hospital, respiratory therapy consultation was solicited at the discretion of the attending physician. We speculated that physicians and residents may have ordered nebulized bronchodilators inappropriately or as a proxy to obtain respiratory therapy consultation. The reduction in bronchodilator use suggests that care managed per protocol with respiratory therapy consultation may reduce unnecessary medication use, which lowers healthcare costs and reallocates vital resources. This finding deserves replication at other hospitals.

This study has several limitations. First, pre-protocol groups were selected retrospectively and it was difficult to ensure that they were similar in acuity to their respective protocol group. For example, Cohort 1 protocol subjects who failed extubation averaged $6 \mathrm{~d}$ between ICU admission and first extubation, compared to $4 \mathrm{~d}$ in the comparison group. This suggests that the protocol population may have had a higher severity of illness than the pre-protocol subjects. Second, we were unable to control for practice or provider differences that affected how cultures were collected in both the retrospective and protocol phases of the study. Cultures were collected using regular standard of care, and we did not set parameters or standards for this practice. Third, HFNC is not available on the general in-patient floor at the study hospital. As such, patients were excluded from the protocol in Cohort 2 if the need for respiratory support escalated on the floor without admission to the ICU. We acknowledge that this may have led to selection bias, favoring inclusion of subjects in Cohort 2 who had more severe respiratory disease. Fourth, the study sample is relatively small and subjects were derived from a mixed ICU population. Results cannot be applied to specific diagnoses or patient populations. Fi- 


\section{HFNC Use in CRitically Ill SubJects}

nally, we selected $4 \mathrm{~L} / \mathrm{min}$ as the threshold for protocol initiation in Cohort 2 to allow for early identification of escalating respiratory support. The next step at the study hospital is to standardize this protocol in the ICU and investigate whether $4 \mathrm{~L} / \mathrm{min}$ is the appropriate threshold for protocol initiation.

\section{Conclusions}

In an undifferentiated ICU population, the use of HFNC at early signs of hypoxemia and per protocol led to a significant decrease in respiratory infections, as well as trends toward shorter duration of HFNC therapy and less delay to definitive care when HFNC fails. These results indicate that there is a benefit to patients when standardized protocols for HFNC guide care decisions.

\section{ACKNOWLEDGMENTS}

The authors thank Catherine Renner for her assistance in the study design, David Blake for his assistance with data collection, and Dustin McCann for helpful comments on the manuscript.

\section{REFERENCES}

1. Chiumello D, Gotti M, Chiurazzi C. High-flow nasal cannula oxygen therapy: physiological effects and clinical data. In: Vincent JL, editor. Annual update in intensive care and emergency medicine 2016. Heidelberg: Springer Verlag; 2016:257-270.

2. Dysart K, Miller TL, Wolfson MR, Shaffer TH. Research in high flow therapy: mechanisms of action. Respir Med 2009;103:1400-1405.

3. Nedel WL, Deutschendorf C, Moraes Rodrigues Filho E. High-flow nasal cannula in critically ill subjects with or at risk for respiratory failure: a systematic review and meta-analysis. Respir Care 2017; 62(1):123-132.

4. Ward JJ. High-flow oxygen administration by nasal cannula for adult and perinatal patients. Respir Care 2013;58(1):98-122.

5. Roca O, Hernández G, Díaz-Lobato S, Carratalá JM, Gutierréz RM, Masclans JR; on behalf of the Spanish Multidisciplinary Group of High Flow Supportive Therapy in Adults (HiSpaFlow). Current evidence for the effectiveness of heated and humidified high flow nasal cannula supportive therapy in adult patients with respiratory failure. Crit Care 2016;20:109.

6. Gaunt KA, Spilman SK, Halub ME, Jackson JA, Lamb KD, Sahr SM. High-flow nasal cannula in a mixed adult ICU. Respir Care 2015;60(10):1383-1389.

7. Stéphan F, Barrucand B, Petit P, Rézaiguia-Declaux S, Médard A, Delannoy B, et al.; on behalf of the BiPOP Study Group. High-flow nasal oxygen vs noninvasive positive airway pressure in hypoxemic patients after cardiothoracic surgery: a randomized clinical trial. JAMA 2015;313(23):2331-2339.

8. Hernández G, Roca O, Colinas L. High-flow nasal cannula support therapy: new insights and improving performance. Crit Care 2017;21:62.

9. Maggiore SM, Idone FA, Vaschetto R, Festa R, Cataldo A, Antonicelli $\mathrm{F}$, et al. Nasal high-flow versus Venturi mask oxygen therapy after extubation: effects on oxygenation, comfort, and clinical outcome. Am J Respir Crit Care Med 2014;190(3):282288.

10. Ni Y-N, Luo J, Yu H, Liu D, Zhong N, Cheng J, et al. Can high-flow nasal cannula reduce the rate of endotracheal intubation in adult patients with acute respiratory failure compared with conventional oxygen therapy and noninvasive positive pressure ventilation? A systematic review and meta-analysis. Chest 2017; 151(4):764-775.

11. Hernández G, Vaquero C, González P, Subira C, Frutos-Vivar F, Rialp G, et al. Effect of postextubation high-flow nasal cannula vs conventional oxygen therapy on reintubation in low-risk patients: a randomized clinical trial. JAMA 2016;315(13):1354-1361.

12. Corley A, Bull T, Spooner AJ, Barnett AG, Fraser JF. Direct extubation onto high-flow nasal cannulae post-cardiac surgery versus standard treatment in patients with a $\mathrm{BMI} \geq 30$ : a randomized controlled trial. Intensive Care Med 2015;41(5):887894.

13. Futier E, Paugam-Burtz C, Godet T, Khoy-Ear L, Rozencwajg S, Delay J-M, et al.; on behalf of the OPERA study investigators. Effect of early postextubation high-flow nasal cannula vs conventional oxygen therapy on hypoxaemia in patients after major abdominal surgery: a French multicenter randomized controlled trial (OPERA). Intensive Care Med 2016;42(12):1888-1898.

14. Hernández G, Vaquero C, Colinas L, Cuena R, González P, Canabal A, et al. Effect of postextubation high-flow nasal cannula vs noninvasive ventilation on reintubation and postextubation respiratory failure in high-risk patients: a randomized clinical trial. JAMA 2016; 316(15):1565-1574.

15. Monro-Somerville T, Sim M, Ruddy J, Vilas M, Gillies MA. The effect of high-flow nasal cannula oxygen therapy on mortality and intubation rate in acute respiratory failure: a systematic review and meta-analysis. Crit Care Med 2017;45(4):e449-e456.

16. Sztrymf B, Messika J, Bertrand F, Hurel D, Leon R, Dreyfuss D, Ricard J-M. Beneficial effects of humidified high flow nasal oxygen in critical care patients: a prospective pilot study. Intensive Care Med 2011;37(11):1780-1786.

17. Frat J-P, Thille AW, Mercat A, Girault C, Ragot S, Perbet S, et al.; on behalf of the FLORALI Study Group; REVA Network. Highflow oxygen through nasal cannula in acute hypoxemic respiratory failure. N Engl J Med 2015;372(23):2185-2196.

18. Parke RL, McGuinness SP, Eccleston M. A preliminary randomized controlled trial to assess effectiveness of nasal high-flow oxygen in intensive care patients. Respir Care 2011;56(3):265-270.

19. Machin D, Campbell MJ, Tan S-B, Tan SH. Sample size tables for clinical studies, 3rd edition. West Sussex, UK: John Wiley \& Sons Ltd; 2009.

20. Schmidt GA, Girard TD, Kress JP, Morris PE, Ouellette DR, Alhazzani W, et al. Liberation from mechanical ventilation in critically ill adults: executive summary of an official American College of Chest Physicians/American Thoracic Society clinical practice guideline. Chest 2017;151(1):160-165.

21. Collins JA, Rudenski A, Gibson J, Howard L, O’Driscoll R. Relating oxygen partial pressure, saturation and content: the haemoglobinoxygen dissociation curve. Breathe 2015;11(3):194-201.

22. Jubran A. Pulse oximetry. Intensive Care Med 2004;30(11):20172020.

23. Jensen FB. Red blood cell $\mathrm{pH}$, the Bohr effect, and other oxygenation-linked phenomena in blood $\mathrm{O} 2$ and $\mathrm{CO} 2$ transport. Acta Physiol 2004;182(3):215-227.

24. American Association for Respiratory Care; Restrepo RD, Walsh BK. Humidification during invasive and noninvasive mechanical ventilation: 2012. Respir Care 2012;57(5):782-788.

25. Williams R, Rankin N, Smith T, Galler D, Seakins P. Relationship between the humidity and temperature of inspired gas and the function of the airway mucosa. Crit Care Med 1996;24(11): 1920-1929. 
26. Franchini ML, Athanazio R, Amato-Lourenço LF, Carreirão-Neta W, Saldiva PH, Lorenzi-Filho G, et al. Oxygen with cold bubble humidification is no better than dry oxygen in preventing mucus dehydration, decreased mucociliary clearance, and decline in pulmonary function. Chest 2016;150(2):407-414.

27. Nyland BA, Spilman SK, Halub ME, Lamb KD, Jackson JA, Oetting TW, Sahr SM. A preventative respiratory protocol to identify trauma subjects at risk for respiratory compromise on a general in-patient ward. Respir Care 2016;61(12):15801587.

28. Kallam A, Meyerink K, Modrykamien AM. Physician-ordered aerosol therapy versus respiratory therapist-driven aerosol protocol: the effect on resource utilization. Respir Care 2013;58(3):431-437.

This article is approved for Continuing Respiratory Care Education credit. For information and to obtain your CRCE

(free to AARC members) visit 